\title{
Design Drivers for Affordable and Sustainable Housing in Developing Countries
}

\author{
John Bruen ${ }^{1}$, Karim Hadjri ${ }^{2}$ and Jason von Meding ${ }^{3}$ \\ 1. School of Planning, Architecture and Civil Engineering, Queen's University Belfast, Belfast BT9 5AG, UK \\ 2. School of Built and Natural Environment, University of Central Lancashire, Preston PR1 2HE, UK \\ 3. School of Architecture \& Built Environment, University of Newcastle, Newcastle 2308, Australia
}

\begin{abstract}
Current demand for housing worldwide has reached unprecedented levels due to factors such as human population growth, natural disasters and conflict. This is felt no more so than in developing countries which have experienced disproportionate levels of demand due to their innate vulnerability. Many current approaches to housing delivery in developing countries continue to utilize inappropriate construction methods and implementation procedures that are often problematic and unsustainable. As such affordability and sustainability are now vital considerations in the international development debate for housing the poor in developing countries in order to meet the long term sustainable development goals and needs of housing inhabitants. This paper utilized an extensive scoping study to examine the various facets impacting on design decision making relative to sustainable and affordable housing delivery in developing country contexts. Aspects of affordability, sustainability, design decision making, appropriate technology use, cultural awareness, as well as current barriers to affordable and sustainable construction in developing countries are examined in detail. Results highlighted the capability of indigenous knowledge, skills and materials as well as selected appropriate technology transfer and cultural awareness by foreign bodies can be utilized in innovative ways in addressing current housing needs in many developing country contexts.
\end{abstract}

Key words: Sustainable housing, low-cost housing, design decision making, affordability.

\section{Introduction}

Shelter is one of the most basic human requirements for survival. The provision of adequate and appropriate housing can be deemed to address this basic need. However, the provision of adequate housing also meets more than human's immediate needs and has the potential to contribute significantly to a wider social, environmental and economic context and to a better quality of life and personal fulfillment for its inhabitants through aspects such as employment generation, knowledge transfer and training, value and cultural continuity and improved health conditions [1]. However, the struggle for adequate housing in many developing countries is considerable and set to continue to rise in future

Corresponding author: John Bruen, B.Sc., B.Arch., M.Sc., RIBA chartered architect, research fields: post disaster management and sustainable housing. E-mail: jbruen01@qub.ac.uk. decades unless addressed.

As such housing is central to much international debate in many developing countries. Vast numbers of people find themselves without adequate shelter due to housing shortages experienced in many of these areas and this is well documented in current literature [2-4]. However, much of the current literature highlights various aspects that impact on the provision of housing in various developing country contexts worldwide without focusing solely on dwelling design and the aspects that impact the designers decision making, i.e., the barriers and drivers of design. This paper provides findings from various developing country contexts to enable the identification of common aspects that impact designer's decision making in various developing country contexts worldwide. Tipple [5] states that it is almost impossible to determine the exact shortage of housing 
in the developing world due to limitations such as insufficient data, little agreement on units of measurement, the length of time data takes to collate and publish and data going out of date very quickly. Housing shortages can often be traced back to two main sources as follows.

\subsection{Pace of Growth of Developing Countries, Governmental Policy and Countries History}

The pace of growth and industrialization in many developing countries has led to rapid urbanization and increases in population. The UNCHS (United Nations Centre for Human Settlements) estimates 95\% of the world's total population growth in the last decade has occurred in developing countries and that these countries will contribute 2 billion new residents during the next 25 years [3]. Between 2007 and 2025, the annual urban population increase in developing regions is expected to be 53 million compared to 3 million in developed regions [3]. This increase has already resulted in severe housing shortages, urban poverty and homelessness in many countries and the development of slums/shanty towns/informal settlements on the periphery of many major cities. As a result, slum dwellers now represent more than $50 \%$ of the population in many developing countries with close to 1 billion people, or $32 \%$ of the world's current urban population, live in slums in inequitable and life-threatening conditions [3]. As such, the informal sector is recognized as the biggest producer of housing in many developing countries [4].

\subsection{Natural Disasters and Conflicts}

The devastation resulting from natural disasters and conflicts is most frequently observed in developing countries due to innate vulnerability and lack of knowledge and resources to adequately implement disaster mitigation strategies or post disaster/conflict recovery strategies. Between 1974 and 2003, 6,367 natural disasters occurred globally, causing the death of 2 million people and affecting 5.1 billion people. A total of 182 million people were made homeless. Of these natural disasters a total of $98 \%$ of the 211 million people affected annually from 1991 to 2000 were in developing countries [2]. The devastation caused by many of these scenarios involves the destruction of much of an area's built environment, i.e., housing (shelter), hospitals, shops, schools etc., services infrastructure (water supply, heat and sanitary requirements) transport infrastructure (roads, rail). The destruction of these basic human requirements has many consequential types of fallout such as health, economic and social upheaval in the affected country.

\section{Methodology}

As the research area is quite broad a scoping study was selected as the most appropriate research method for this review in order to summarize the key findings from all available literature and also to identify the potential gaps. This approach is particularly relevant to this particular study as there are numerous sources of information available from various organizations and bodies, i.e., academic journals, industry journals, international housing organizations, NGOs (non-governmental organizations) etc.. In-depth and broad findings on the topic were sought from current available literature to enable conclusions and findings to be disseminated to relevant stakeholders who may lack the time or resources to undertake the study themselves i.e. designers, policy makers, community organizations, NGO's. Arksey and O’Malley [6] state that scoping studies are appropriate in this context as they are guided by a requirement to identify all relevant literature regardless of study design as opposed to been guided by a specific research question as may be the case in a systematic literature review.

A five point framework developed by Arksey and O’Malley [6] was utilized for this scoping study. This framework firstly consisted of developing a research question, secondly identifying the relevant literature, 
thirdly selecting the relevant literature, fourthly charting the data and finally summarizing and reporting the findings in a concise manner. The selected research question was broad in nature to cover the main aspects to be covered by the study: "What are the main barriers and design drivers for affordable and sustainable housing in developing countries?”

In keeping with Arksey and O’Malley [6] proposed framework and in order to generate a broad range of coverage an extensive approach using selected keywords was utilized to identify relevant data. This consisted of journal publications searches in major registers such as Avery, INFORM Global, Zetoc, Web of Science and Compendex. A further internet search using Google Scholar was utilized to further expose publications or grey literature. Bibliographies and references were studied to locate further useful information for the study. Website searches of suitable reputable organizations such as Un-Habitat, national and international housing NGOs, housing charities and open access journals, were examined for relevant information, i.e., field reports, policies, case studies etc.. The latter approach is quite a relevant data collection method in relation to this particular topic as open access to information and knowledge transfer, with the aim of improving housing for the poor in developing countries, is an aspiration of many organizations operating in the field of housing provision in developing country contexts and the making available of their information is to be commended.

Following elimination of irrelevant studies a total of 649 references were identified from the various searches outlined. Following further in-depth reading of titles and abstracts 154 were selected for further reading of which 55 were used in the final reference list. Mapping of the findings were divided into various headings and sub heading to address the overall research question. The overall main headings consisted of: (1) barriers and challenges to sustainable construction in developing countries; (2) main design drivers with the potential to contribute to affordable and sustainable housing in developing countries.

\section{Current Approaches to Housing Design and Delivery}

The two main causes of housing shortages outlined share many commonalties in that in both situations should the housing shortage be addressed using conventional unsustainable construction techniques then the environmental effect alone of this approach would be devastating considering the vast scale of housing required in developing countries. While the majority of efforts by decision makers such as governments, NGOs, CBOs (charity based organizations), etc. to address housing shortages have the best intentions of people central to their efforts, the literature highlights that the current approaches to housing shortages often involve a top down approach. This means that many communities are not involved in participation to the level that they should be to ensure their short and long term settlement needs are satisfied in an appropriate manner.

The global shortage of housing requires appropriate, affordable and sustainable responses that cater to severely affected regions worldwide. Erguden [1] highlights that policies and approaches for housing in developing countries have evolved over the past number of decades from one centered on government provided social housing to one of self-help to the current common approach of enablement in which all parties support a people centered housing process to obtain housing delivery goals. Although the enablement based approach is generally considered to be the most appropriate many approaches currently fall well short of the desired aspirations in relation to affordability and sustainability. Reffat [7] states that the concept of sustainability has only recently been introduced into developing countries construction industries and that sustainability and sustainable 
construction are not yet an essential part of the decision making process. Traditionally, affordability in mainstream housing markets is associated with economic and social sustainability with little emphasis on environmental sustainability [8]. Perceived higher costs and underlying socio-cultural factors also contribute to the lower levels of social acceptability of sustainable construction in the main stream affordable housing market [9, 10]. Global inequalities and economic constraints in many developing countries have also resulted in pragmatic governance decision making in relation to sustainable social and environmental goals being made more difficult [11]. In many instances, organizations have to provide housing to meet the immediate term shelter needs of large populations, at times due to natural disasters or conflicts, and this is often given priority over long term aspects such as sustainable design, participation and reference to local materials and techniques. Sustainability is thus often perceived as an additional cost to standard practice and is not a necessity but rather a luxury of the rich [7, 12].

Many current approaches to housing provision are left to what professionals from the formal sector and international bodies consider the most appropriate solution which is often at odds with the expectations of the future house inhabitants and environmental ideals [13, 14]. Many current approaches often employ a one hat fits all or quest for a universal approach to addressing the current housing shortage in developing countries. Often these approaches involve imported industrialized materials, western construction techniques and typologies not common to the surrounding context. This is often due to the perception that the "west knows best" and these solutions are deemed to be associated with wealth, progress, prosperity and globalization. This is a flawed belief and demonstrates a clear lack of understanding and vision on behalf of the different decision makers involved in implementing these approaches. This often results in rigid monotonous constructions and typologies which ironically can have negative effects on the end users long term needs and wellbeing, i.e., replacement of traditional settlements with modern towns and lack of cohesion between the town's inhabitant leading to socio-cultural and economic negative effects [15]. The manufacture and import of many of the materials used also result in houses that are not affordable for the masses of population that require them [16] as well as being environmentally unsustainable.

\section{Barriers and Challenges to Sustainable Construction}

Various literature [4, 17-25] highlights the common barriers faced in trying to implement sustainable construction in developing countries:

- Environmental sustainability is often a low priority in developing countries, and the need for immediate shelter is primary for the majority;

- Psychological and sociological issues in relation to use of alternative materials and its acceptability by people, i.e., status of certain materials deemed for the poor only;

- Effects of globalization and desire of many to imitate housing approaches of the west leading to inappropriate imported typologies, materials, designs etc.;

- Lack of overall holistic approach to sustainable design, i.e., social, cultural, economic and environmental;

- Lack of training and education in sustainable design and construction leading to lack of necessary design and building skills available;

- Lack of access to adequate information and knowledge on sustainable development and design;

- Inadequate government planning and policy making;

- Perceived higher cost of sustainable building approaches;

- Scarcity of professional capabilities, i.e., designers and project managers; 
- Lack of demonstration examples of best practice sustainable construction approaches;

- Disincentive factors over local material production, i.e., government supplying alternative imported materials;

- Need to develop cost effective construction technologies;

- Building materials are becoming ever more expensive. Need to utilize locally available materials to suit local typologies;

- Lack of guidelines available on selection of appropriate building approaches and packages, i.e., materials, methods, designs, equipment;

- Unaffordable land and housing prices and lack of land tenure;

- Inadequate housing finance systems;

- Lack of support of small scale construction industries;

- Inefficient or inadequate implementation strategies;

- Lack of research and experimental findings;

- Lack of implementation and promotion of research findings on appropriate approaches;

- Gradual vanishing of traditional wisdom and knowledge on local material and construction techniques;

- Historical legacies of race and class;

- Lack of government or political backing to sustainable development;

- Inappropriate procurement systems;

- Inability to adopt best practice;

- Bureaucratic impediments to the implementation of housing;

- Inappropriate building regulations;

- Lack of consultation and capacity building with housing inhabitants;

- Poor housing management and planning policies at both a national and local scale in many countries.

In order to address these barriers and challenges a clear and concise design approach is required to identify them from the outset of projects and propose methods of enabling designers and other stakeholders to address them so as not to have a detrimental effect on the long term overall affordability and sustainability goals of the project.

\section{Main Design Drivers with the Potential to Contribute to Affordable and Sustainable Housing in Developing Countries}

This study focused primarily on the design considerations of appropriate and suitable low-cost sustainable housing to meet current shortages. The literature indicates that in relation to the design of dwellings there are three main broad areas that offer the potential to significantly contribute to the provision of affordable and sustainable housing in developing countries.

\subsection{Appropriate Design and Material Selection}

Efforts to address immediate housing needs should simultaneously address the long term needs and sustainability of the communities which they intend to serve in terms of social, economic and environmental sustainability [17]. The increasing demand for housing has resulted in an urgent need for crucial research into new design approaches and use of alternative materials in housing delivery [17]. Mehta and Beidwell [26] argue that increasing the quality of life in developing countries requires optimum use of local natural resources and labor over imported materials, increasing the potential for greater affordability.

Material supply has been recognized by many as one of the main contributors to the provision of affordable and sustainable housing, contributing up to $70 \%$ of the total direct costs of housing construction [25, 27-30]. The use of localized materials, skills and construction techniques in design has the potential to dramatically reduce the cost of housing compared to westernized techniques, while simultaneously contributing to sustainable housing solutions [31-35]. 


\subsection{Participation, Knowledge Transfer and Use of} Appropriate Innovative Technology Specific to Developing World Contexts

Despite the fact that over two thirds of the world's population live in developing countries, to date the developed world has led the way in global environmental destruction [36]. It is also developed countries that have dominated research in relation to sustainable construction, much of which is aimed specifically towards a developed country context. This has led at times to a non holistic approach to sustainable housing with technical cost reduction measures often employed to a large degree with little consideration given to what housing means for its users [37]. Many current approaches result in conflicting and competitive issues in technological economic sustainability verses cultural and social sustainability [18]. There is recognition that sustainable development approaches and technologies established in the west are not always desirable and the evidence shows that if not implemented correctly, these approaches will prove unsuccessful [24, 37, 38]. New approaches need to be adopted for the vastly different contexts within developing countries and local conditions, knowledge and culture must be given full recognition [39].

Participation by relevant stakeholders in all stages of the design and delivery process has been recognized as an appropriate approach to housing provision in developing country contexts [40-43] Knowledge creation, exchanging and sharing of skills, knowledge and experiences between the relevant stakeholders are recognized as effective approaches in ensuring technical, cultural, economic and environmental aspects of housing design and delivery are addressed in an appropriate manner [1]. The use of appropriate technology should work in conjunction with design and materials and should correspond to local conditions and culture and be durable, reliable, require a minimum of maintenance and be fit for modern living [27, 44].
Plessis [4] argues that although the level of development required in developing countries may be a cause of despair it can also be seen as an opportunity to learn from developed nations, avoid the problems experienced by developed countries, and follow a more sustainable development path, of which housing will play a major part. In addition, Plessis [45] argues there is no clear guidance as to what sustainable development of the built environment means and how sustainable development can be incorporated into the decision making process, further adding that the academic debate in developed countries has little to offer except where applies to the hi-tech world of the West. She further states that in order for sustainable development to be effectively addressed societies can not isolate themselves and two way communication and dialogue between developing and developed countries is required. This sentiment is backed by Cole and Lorch [46] who argue that environmental issues require international cooperation in setting agendas, targets, assessments and standards as well as the sharing of sound environmental knowledge and practice.

Much of what we know as transfer of knowledge is attributed to factors such as globalization and advanced technology and communications. However, Oliver [47] highlights that cross cultural transfer and exchange of knowledge and ideas has always existed, it is just that it has never existed at such an accelerated rate due to modern technology and globalization. Vellinga [48] notes that globalization and the transfer of technology between different cultures need not necessarily be a cultural treat and that cultural hybridity is nothing new, stating that the important factor that influences its acceptance and success is the opportunity to appropriate it to local traditions, ways of life, cultural values and customs. As such Vellinga [48] states that globalization can best be regarded as an infrastructure which facilitates the appropriate exchange and transfer of new ideas and practices including green technologies for the built 
environment.

\subsection{Design Decision Making Assistance and Assessment Tools}

Fray and Yaneske [49] suggest that the problem with many responses to sustainability is that decisions are made with limited knowledge and information. Building and construction play an important role in supporting sustainable development in developing countries and as a consequence the vast demand for housing is a significant issue that must be prioritized. However, it is recognized that the relationship between the two is a complex one and that an assessment framework and structured approach are effective methods to integrate sustainability into buildings in developing countries [7, 50]. Sustainable assessment tools to date have mainly focused on a developed world context [51] and focus mainly on technological solutions. Aside from established assessment tools from developed nations, i.e., BREEAM (UK), LEED (US), GBTool (Multi National), EcoHomes (UK) there is little in the current literature to demonstrate the existence of any main assessment tool specifically directed to sustainable housing in developing countries. However, the need to develop context specific assessment tools for developing countries that cater for a wider group of stakeholders has been recognized, given that existing developed country tools are not deemed appropriate [51-57].

\section{Conclusions}

This paper presented the findings of a scoping study examining the various aspects impacting on the design and delivery of affordable and sustainable housing in developing country contexts worldwide. The paper utilized various relevant information sources to identify the main design barriers and challenges designers operating in housing provision in developing country context face and should be aware of from the outset of their design projects. The study further recognizes three drivers for design that if utilized could offer the potential to significantly contribute to the provision of appropriate housing design and delivery in developing country contexts.

The study focused on aspects of sustainability beyond environmental aspects alone and addressed aspects such as economic and social elements which all form the triple bottom line many experts associate with sustainable design. It is concluded that the aspects identified in this study can be addressed through an informed design decision making process which considers the various design challenges, barriers and drivers as identified in this study. This paper will assist in the decision making of the various bodies and professions responsible for implementing housing design and provision in developing country contexts, i.e., governmental bodies, policy makers, NGOs, CBOs, planners, architects, engineers and developers.

This paper utilized information sources based on many different developing country context worldwide to identify design barriers, challenges and drivers that are common to developing country contexts at large in order to enable design practitioners in developing countries to ensure these aspects are given due consideration in their design decision making process. The author recognizes that many individual developing country contexts, or regions within developing countries, will have individual or region specific factors that will require more in-depth study by designers operating within that context in order to fully establish local design considerations in sufficient specific detail to ensure appropriate design responses for that specific region. As such further research studies on individual developing country contexts by both academics and practitioners of individual countries or regions will enable more region specific detail to be obtained under the various design consideration aspects identified within this paper and add to the knowledge base for designers operating in that specific region or country. Appropriate dissemination of design knowledge gained from 
individual contexts research is essential to ensure that the various potential users identified above have access to the relevant knowledge and guidance and that it is utilized to its full potential in practice.

\section{References}

[1] S. Erguden, Low-cost housing: Policies and constraints in developing countries, in: International Conference of Spatial Information for Sustainable Development, Nairobi, Kenya, Oct. 2-5, 2001.

[2] Enhancing Urban Safety and Security-Global Report on Human Settlements 2007, UN-HABITAT (United Nations Human Settlements Programme), Earthscan, London, 2007.

[3] Planning Sustainable Cities: Global Report on Human Settlements 2009, UN-HABITAT (United Nations Human Settlements Programme), Earthscan, London, 2009.

[4] C. du Plessis, Agenda 21 for Sustainable Construction in Developing Countries: A Discussion Document, CSIR Building and Construction Technology, Pretoria, 2002.

[5] G. Tipple, Extending Themselves: User-Initiated Transformations of Government Built Housing in Developing Countries, Liverpool University Press, Liverpool, 2000.

[6] H. Arksey, L. O’Malley, Scoping studies: Towards a methodological framework, Int. J. Social Research Methodology 8 (1) (2005) 19-32.

[7] R. Reffat, Sustainable construction in developing countries, in: Proceedings of First Architectural International Conference, Cairo University, Egypt, 2004.

[8] B. Randolph, M. Kam, P. Graham, Who can afford sustainable housing, in: A. Nelson (Ed.), Steering Sustainability in an Urbanizing World, Ashgate, Aldershot, United Kingdom, 2008.

[9] L. Buys, K. Barnett, E. Miller, C. Bailey, Smart housing and social responsibility: Learning from the residents of Queensland's research house, Australian Journal of Emerging Technologies and Society 3 (1) (2005) 43-47.

[10] J. Sibley, D. Hes, F. Martin, A triple helix approach: An inter-disciplinary approach to research into sustainability in outer suburban housing estates, in: Proceedings of Methodologies in Housing Research Conference, Stockholm, Sep. 2008.

[11] C. Sneddon, R. Howarth, R. Norgaard, Sustainable development in post Brundtland world, Ecological Economics 57 (2006) 53-268.

[12] P. Brandon, P. Lombardi, Evaluating Sustainable Development, Blackwell Science, UK, 2005.

[13] G. Lizarralde, C. Davidson, Learning from the Poor, IF Research Group, Faculté de l’Aménagement, Université deMontréal, Canada, http://www.grif.umontreal.ca/pages/ lizarralde_gonzalo.pdf (accessed Mar. 15, 2011).

[14] A. Fallahi, Lessons learned from the housing reconstruction following the Bam Earthquake in Iran, The Australian Journal of Emergency Management 22 (1) (2007) 26-35.

[15] Y. Kakabadse, The Essence of Sustainable Construction in on the Road to Sustainability-A Collection of Short Contributions from International Proponents of Sustainable Construction-Holcim awards June 2005, http://www.holcimfoundation.org/T702/HolcimAwards.h m (accessed Mar. 15, 2011).

[16] A.Y. Adeyemi, Affordable housing production: The influence of traditional construction materials, in: 30th IAHS World Congress on Housing, Housing Construction: An Interdisciplinary Task, Wide Dreams-Projectos Multimédia, 2002, pp. 827-832.

[17] Un-Habitat, Low-Cost Sustainable Housing, Materials + Building Technology in Developing Countries-Shelter Initiative for Climate Change Mitigation, www.gltn.net/....low-cost-sustainable-housing-materialsbuilding-technology-in-developing-countries...-/downloa d.html (accessed Mar. 3, 2011).

[18] N. Islam, Sustainability issues in urban housing in a low-income country: Bangladesh, Habitat International 20 (3) (1996) 377-388.

[19] A. Ngowi, Challenges facing construction industries in developing countries, Building Research \& Information 30 (3) (2002) 149-151.

[20] A. Goebel, Sustainable urban development? Low-cost housing challenges in South Africa, Habitat International 31 (2007) 291-302.

[21] G. Ofori, Challenges facing the construction industry in developing countries, in: Proceeding of 2nd International Conference on Construction in Developing Countries, Gaborone, Nov. 15-17, 2000.

[22] F. Shafii, Achieving sustainable construction in the developing countries of South East Asia, in: Proceedings of the 6th Asia-Pacific Structural Engineering and Construction Conference (APSEC 2006), Kuala Lumpur, Malaysia, Sep. 5-6, 2006.

[23] R.K. Celly, Low cost energy efficient and environmental-friendly housing technologies for developing countries, in: Sanjaya Lall Memorial Conference on India-Africa Cooperation, Trade and Investment, New Delhi, Sep. 10-14, 2007.

[24] The Provisional Agenda Appropriate, Intermediate, Cost-Effective Building Materials, Technologies and Transfer Mechanisms for Housing Delivery, United Nations Centre for Human Settlements (UNCHS), 1992, http://www.unhabitat.org/downloads/docs/3636_21919_ HS-C-16-2-Add_2.htm (accessed Mar. 15, 2011).

[25] J. Wells, Population, settlements and the environment: The Provision of organic material for shelter, Habitat 
International 19 (1) (2005) 73-90.

[26] R. Mehta, L. Beidwell, Innovative construction technology for affordable mass housing in Tanzania, East Africa, Construction Management and Economics 23 (2005) 69-79.

[27] J. Wells, S.H. Sinda, F. Haddar, Housing and building materials in low-income settlements in Dar es Salaam, Habitat International 22 (4) (1998) 397-409.

[28] M.S. Zami, A. Lee, Using Earth as a Building Material for Sustainable Low Cost Housing in Zimbabwe, The Built \& Human Environment Review, 2008.

[29] P. Tiwari, Sustainable practices to meet shelter needs in India, Journal of Urban Planning and Development 29 (2) (2003) 65-83.

[30] D.R. Moore, N. Ahmed, Proposal for the development of an indigenous materials and methods-Oriented design data aid for design professionals practicing in developing nations, Habitat International 21 (1) (1997) 29-49.

[31] M.S. Zami, A. Lee, Economic benefits of contemporary earth construction in low-cost urban housing-State-of-the-art review, Journal of Building Appraisal 5 (2010) 259-271.

[32] K. Hadjri, M. Osmani, B. Baiche, C. Chifunda, Attitude towards earth building for Zambian housing provision, in: Proceedings of the ICE Institution of Civil Engineers, Engineering Sustainability 160 (2007) 141-149.

[33] A.O. Olotuah, Recourse to earth for low-cost housing in Nigeria, Building and Environment 37 (2002) 123-129.

[34] D. O’Brien, I. Ahmed, D. Hes, Housing reconstruction in Aceh: Relationships between house type and environmental sustainability, in: Conference Proceedings, Building Abroad-Procurement of Construction and Reconstruction Projects in the International Context, Montreal, Oct. 2008, pp. 361-370.

[35] K.J. Charles, U. Paul, Low cost construction technologies and materials-Case study Mozambique, in: Proceedings of the 11th International Conference on Non-conventional Materials and Technologies (NOCMAT 2009), Bath, UK, Sep. 6-9, 2009.

[36] B. Hamm, P.K. Muttagi, Sustainable Development and the Future of Cities, Intermediate Technology Publications, London, 1998.

[37] R. Lorch, Sustainable development and regionalism, Building Research \& Information 33 (5) (2005) 393-396.

[38] E. Cromley, Cultural embeddedness in vernacular architecture, Building Research \& Information 36 (3) (2008) 301-304.

[39] S. Guy, Cultures of architecture and sustainability, Building Research \& Information 33 (5) (2005) 468-471.

[40] V.O. Cigdem, E. Yalciner, G. Nilufer, Local participatory mechanisms and collective actions for sustainable urban development in Turkey, Habitat International 35 (2011)
9-16.

[41] M. Holden, M. Roseland, K. Ferguson, A. Perl, Seeking urban sustainability on the world stage, Habitat International 32 (2008) 305-317.

[42] A. Maskrey, Disaster Mitigation: A Community Based Approach, Oxfam, Oxford, 1989.

[43] M.B.G. Choguill, A ladder of community participation for underdeveloped countries, Habitat International 20 (3) (1996) 431-444.

[44] C. Ebsen, B. Rambol, International review of sustainable low-cost housing projects, in: Proceedings of Strategies for a Sustainable Built Environment, Pretoria, Aug. 23-25, 2000.

[45] C. du Plessis, Sustainable development demands dialogue between developed and developing countries, Building Research \& Information 27 (6) (1999) 378-379.

[46] R.J. Cole, R. Lorch, Buildings, Culture and Environment, Informing Local \& Global Practice, Blackwell Publishing, Oxford, 2003.

[47] P. Oliver, Technology Transfer-A Vernacular View, in Buildings, Culture and Environment, Informing Local \& Global Practice, Blackwell Publishing, Oxford, 2003.

[48] M. Vellinga, Sustainable architecture in an age of gentle apocalypse, Building Research \& Information 32 (4) (2004) 339-343.

[49] H. Frey, P. Yaneske, Visions of Sustainability: Cities and Regions, Taylor \& Francis, New York, USA, 2007.

[50] J. Gibberd, Building Systems to Support Sustainable Development in Developing Countries, Facilities Planning and Management, CSIR Building and Construction Technology, Pretoria, 2003.

[51] J. Gibberd, Assessing sustainable buildings in developing countries-The sustainable building assessment tool (SBAT) and the sustainable building lifecycle (SBL), in: 2005 World Sustainable Building Conference, Tokyo, Sep. 27-29, 2005.

[52] H.H. Ali, S.F. Nsairat, Developing a green building assessment tool for developing countries-Case of Jordan, Building and Environment 44 (5) (2009) 1053-1064.

[53] Y. Liu, D. Pradad, D. Li, J. Liu, Developing regionally specific environmental building tools for China, Building Research \& Information 34 (4) (2006) 372-386.

[54] J.A. Todd, S. Geissler, Regional and cultural issues in environmental performance assessment for buildings, Building Research \& Information 27 (4-5) (1999) 247-256.

[55] E. Kaatz, D. Root, P. Bowen, Broadening project participation through a modified building sustainability assessment, Building Research \& Information 33 (5) (2005) 441-454.

[56] J. Turner, Tools for building community: An examination of 13 hypthosis, Habitat International 20 (3) (1996) 339-347. 